\title{
Impediments to Effective Youth Participation in Rural Community Development
}

\author{
Hlekani Muchazotida Kabiti, Joseph Francis and Simbarashe Kativhu \\ Institute for Rural Development, University of Venda, Private Bag X5050, \\ Thohoyandou 0950, South Africa
}

KEYWORDS Attitude. Decision Making. Relationship. Youth Leadership

\begin{abstract}
This paper is based on a study conducted in Makhado Municipality of Vhembe District, South Africa. It sought to unearth the factors hindering youth participation in community development. In this sequentially integrated mixed methods study, respondents in phase 1 were purposively sampled. Data were collected in reflection circles established considering gender. The results of the first phase were consolidated into a questionnaire requiring responses on a 10 point Likert-type scale. In phase 2 the questionnaire was administered to the same categories of youth in reflection circles. Descriptive statistics and nonparametric tests for significant differences across gender categories and hindering factors were computed using the Statistical Package for Social Sciences. No significant gender differences were raised. It was concluded that youth desire opportunities to demonstrate their community leadership abilities. The need for change in leaders' attitudes regarding the role of youth in development work is evident.
\end{abstract}

\section{INTRODUCTION}

The world youth population was estimated at 50.5 percent and is expected to continue expanding (Euro Monitor International 2012). The population of young people below 30 years is around 70 percent of the total population in SubSaharan Africa (Euro Monitor International 2012). Thus youth are critical population subgroup which can be effectively utilized to increase productivity across the world. The possibility of youth driving community development particularly in under-resourced developing countries is even more apparent (Lucie et al. 2016). However, youth contribution to community development can only be realized through their active involvement in various activities. As such, there is global cognizance of the need to include youth in decision making with regards to development and also acknowledge the value they can add in the process.

Participation is broadly viewed as a means to increase the involvement of a country's residence to enhance their competences. Therefore, it is a vehicle for influencing decisions that in-

Address for correspondence:

Simbarashe Kativhu

University of Venda Private Bag x5050

Thohoyandou, South Africa

Telephone: +27631096440,

E-mail:kativhus@gmail.com fluence young people's lives as well as the communities they reside in (Chess and Purcell 2009). Youth participation in community work is a practical process through which the beneficiaries influence the initiation and management of community development work rather than being passive onlookers (Angba et al. 2009). Nikkhah and Redzuan (2009) further demonstrate that community participation creates an enabling environment for sustainability by allowing community beneficiaries to initiate, guide projects and make decisions about their development projects. Youth active participation is viewed as a critical component of economic development and a critical pillar towards alleviating poverty (Dundumaro and Madulu 2011). Given this background, it is vital to find ways of promoting youth participation in community development work, as a pre-requisite to addressing socio-economic marginalization and poverty in communities.

Youth participation in community development work is influenced by various factors. The common factors include personal characteristics and financial capacity (Ovwigho 2004). A study in Nigeria found that education levels determine youth participation in community work (Angba et al. 2009). Bridges et al. (2001) also found that educated youth participated more in rural development programs. Thus, a higher education level is positively linked to participation. Socio-cultural factors that entail communi- 
ty values, customs, beliefs and traditions also influence youth engagement in development work (Lucie et al. 2016). In this regard, understanding culture helps to understand the barriers to youth actions, the behavior of community leaders and barriers to participation.

Youth are considered to be critical for the future success of any community. Thus, engaging them in community-related issues is an inevitable investment for the future (Campbell and Erbstein 2012). As a result, there is growing support for youth participation in community development work particularly in Africa (Lucie et al. 2016). Various national and international regulations on youth inclusive development have also been established to promote youth participation. These include the African Youth Charter (2006), Commonwealth Youth Charter (2005), Commonwealth Plan of Action for Youth Empowerment (PAYE) 2007-2015. However, most of these initiatives do not reflect youth voices as they were developed using the top-down approach (Kativhu et al. 2017). As such, they often fail to address practical challenges that hinder youth active engagement in community development work.

In South Africa, youth are not given enough opportunities to engage in community work as agents of their own broader success (Jobson 2011). Approximately 70 percent of youth do not actively participate in community activities at all levels (Benson 2012). Lucie et al. (2016) concurred that youth participation in communitybased projects remains minimal in South Africa. On one hand, this reflects the youth's lack of interest to contribute to development. However, Booyens and Crause (2012) argue that there are inadequate prospects for youth to participate in community activities. This clearly shows that the barriers to youth participation in community development work are not well understood. As a result, Benson et al. (2006) recommended that more efforts are required to find ways of involving young people in civic development activities.

\section{Theoretical Framework}

This community youth development theory guided this paper. The theory emphasizes the importance of changing the community environment where youth reside. This encompasses engaging them in the community development process to enhance their holistic growth as well as community objectives (Benson and Pittman 2001). The same scholars further highlight that utilizing the strengths of individuals and the community may lead to positive change. The theory further recognizes youth work as drivers of community development and transformation. Thus, combining youth and community development is crucial especially when taking cognizance of the factors that have weakened the Africa values of interdependence that have been fast replaced by western individualism values (United Nations Commission for the Refugees: UNHCR 2010). This change is credited to changed community structures, changing cultural practices and changed family circumstances. Rhodes and DuBois (2006) argue that these changes impact youth development trajectories, embracement of available opportunities and services, as well as their position in the community. This adversely limits the support base for youth in the community. However, the factors determining youth involvement in community development may differ with location and circumstances. Based on this theory the current paper sought to establish factors hindering active youth involvement in community development work in Thulamela municipality. Finding areaspecific hindrances to participation helps to unlock customized approaches for promoting youth involvement in community activities.

\section{Objectives}

The main objective of the study was to establish the factors that inhibit youth participation in community development. The paper also seeks to identify the sources of the barriers to youth participation in community development work.

\section{METHODOLOGY}

The study was undertaken in Ward 17 of Makhado Municipality, in Limpopo province of South Africa. Makhado municipality has a total population of 516 301, drawn out of 134889 households (STATSSA 2013). The municipality is composed of 38 wards which comprise of several villages. Ward 17 has a total population of

Anthropologist, 37(1-3): 1-7 (2019) 
12,921 (STATSSA 2013) and is made up of 5 villages namely Sherly, Shihlobyeni, Njahkanjhaka, Riverplaast and Magangeni.

Data were collected through sequentially integrated mixed methods (qualitative and quantitative methods). In the first phase, respondents were purposively sampled from the five villages that constitute Ward 17 of Makhado. A total of 148 respondents were selected and grouped into 13 reflection circles ( 7 female youth groups and 6 male youth groups), for the study. Data were collected through focused group discussions. The groups were categorized according to gender, the village of residence and school-going status. Semi-structured interview guides were used to obtain data in this phase. Semi-structured interview guides were ideal for collecting in-depth data regarding the barriers to youth participation. Therefore, the first phase was meant for understanding youth perceptions regarding the obstacles to participation in community development work. Data were analyzed following the thematic system procedures.

Results from the first phase were consolidated into a questionnaire requiring responses on a Likert-type scale of 1 (strongly disagree) to 10 (strongly agree). Reflection circles were also organized in phase 2 during which the questionnaire was administered to the same categories of youth. The purpose of this phase was for respondents to prioritize the factors they had identified in the first stage. The Statistical Package for Social Sciences version 22 was used to analyze data. Data were tested for normality using the Shapiro-Wilk Test for Normality since the sample size was small. An Analysis of Variance test was then carried out for the factors which were found to be normally distributed. The Mann-Whitney nonparametric test was then carried out to test for the significance of the effects of gender categories on each factor hindering youth participation. Descriptive statistics were also processed to determine the distribution of the factors through the mean and standard deviation.

\section{RESULTS}

The respondents raised several factors as a hindrance to participation in community development activities. The 17 identified factors were grouped into three themes namely relationship, attitude and leadership. The exact factors raised and their respective means are shown in Tables 1,2 and 3 . The results indicate the level of diversity of the factors that hinder youth participation. Also included in the tables are statistical calculations carried out from the data collected. From the Tables, Shapiro-Wilk test results indicate that most of the factors raised were normally distributed except for five. This paved the way for a one-tailed Analysis of variance on the normally distributed factors. Results in the same Tables show that there were no significant differences in the level of agreement to the factors between male and female groups. The MannWhitney U test was further carried out to determine if there were any significant differences between the male and female groups regarding their level of agreement to all the 17 identified factors. The results indicated that there were no differences between these two groups. Although male and female youth had different needs, the study indicated no difference with regards to their requirements for active participation in community development activities. This implies that actions taken to address this challenge do not necessarily need to factor in gender differences.

\section{Relationships with Community Adults}

Good working relationships were reportedly vital for the active participation of youth. The results shown in Table 1 indicated that adults did not involve youth concerning community issues. This factor had the highest mean (7.31), indicating that the study participants agreed more to it. Without being involved, it is difficult for youth to get any information about the current issues or activities happening within their community. Lack of knowledge also resulted in the youth not participating since they were not aware of what was happening in the community. The fact that adults do not involve youth indicated a problem in the relationship between these two groups.

\section{Favoritism}

Results also showed that there was no fair treatment among youth in the community. Favoritism was apparent based on social value and

Anthropologist, 37(1-3): 1-7 (2019) 
HLEKANI MUCHAZOTIDA KABITI, JOSEPH FRANCIS AND SIMBARASHE KATIVHU
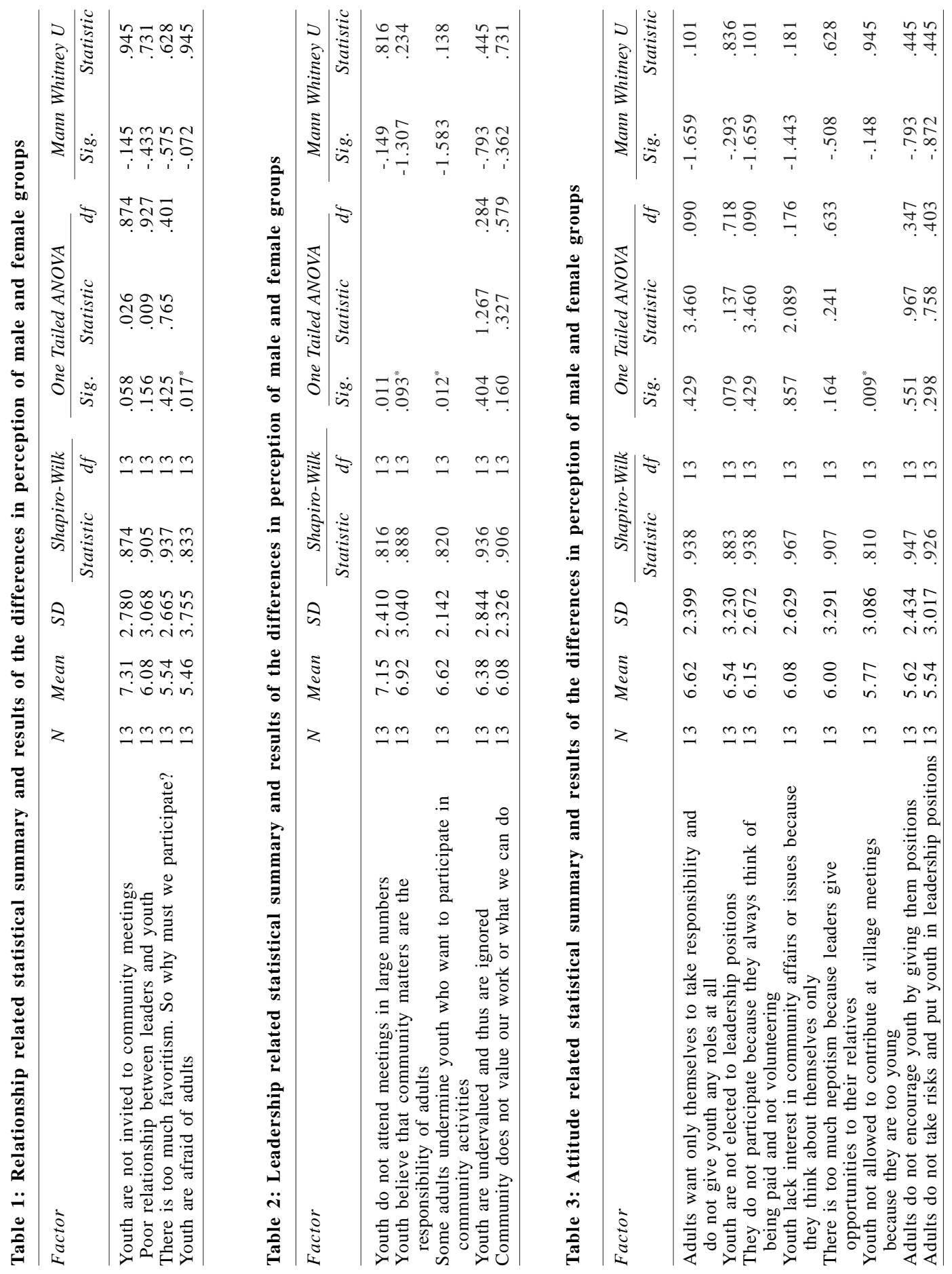

Anthropologist, 37(1-3): 1-7 (2019) 
political influence grounds. The on sided preferential system normally derailed the passion for participation for some of the youth. A small circle of those who were favored normally continued participating. This resulted in the misrepresentation of the community and its needs. Usually, the relatives and friends of those in leadership positions were the ones who benefited from the favoritism system. This was a drawback to development in a democratic society.

\section{Exclusion from Leadership Positions}

Several factors related to leadership structures were also raised as hindrances to youth participation in community development activities (Table 2). Since most of the leadership positions were currently held by the adults in the community, youth were not legible for leadership positions. Without their inclusion in leadership positions, youth could not influence decisions in the community. As a result, the youth remained marginalized in as far as community development initiatives were concerned.

\section{Undermining Youth}

Most youths were also not allowed to contribute at village meetings. Consequently, this demotivated them from attending community meetings late alone to engage in community work. In most cases, youth were called upon to work on adult initiated activities. As a result of the above-mentioned factors, it was difficult for youth to make a substantial contribution or to participate in community activities if they were not given the opportunity to do so. However, results also indicated that some of the youth were not interested because they lacked community patriotism and philanthropic ideologies. This could be as a result of ignorance of the amount of self-benefit which can be acquired from participating in community development activities. Such youth need to be exposed to youth development practices.

\section{The Desire for Payment}

Some of the youth were only interested in paid opportunities rather than volunteering as illustrated by statistical results (Mean= 6.15).
Such youth would not engage in any matter where they will not receive an immediate financial benefit. Besides monetary gains, other youth desired material rewards such as clothes and food in exchange for their services. High unemployment rates among youth in the community precipitated their quest for rewards.

\section{Attitude Issues}

Results revealed that community adults were ignorant about youth needs and to some extent manipulative. In this regard, adults neither recognized no appreciated youth participation in community development work. This contributed negatively to youths' confidence in their ability to be active citizens of the community and thus resulting in apathy. As a result of the continuous undermining, youth lost interest in community participation. It is therefore critical for adults to appreciate the contribution of young people in all community initiatives.

\section{Negative Attitude towards Participating}

As illustrated in Table 3, some of the youth believed that community matters ere the responsibility of adults (Mean=6.92). Such youth were unaware of what participation entails and how it affects them. The youth did not view community development as their responsibility was more likely to avoid community development meetings and engagements as illustrated by a high mean (7.15).

\section{DISCUSSION}

Results illustrated that youth views were suppressed by adults in the community. As a result, there was no clear communication between adults and youth. Checkoway (2011) also echoed the same sentiments that, youth participation in community matters is normally mediated by adults. As a result, when the relationship between these two groups is underlined by inequalities, youth participation might be difficult to facilitate. Therefore, the unequal relationship between youth and adults in the Makhado area derailed youth participation in community development work. This kind of relationship emanates from social values that denote that adults 
hold authority over the youth (Mokwena 2002). Lucie et al. (2016) also highlight that, socio-cultural factors such as norms and beliefs determine the extent to which youth can participate in community development work. Given this background, there is a need to create a more power balanced working relationship between adults and youth to destroy the existing cultural hindrances to participation.

Youth omission from leadership positions was also evident. This suggests that youth were still marginalized with little opportunities to contribute to decision making and community activities. Toffler (2005) notes that when youth are not given leadership positions, they tend to withdraw form community engagement. Despite the limited involvement of youth in leading positions, the National Youth Policy (NYP) 2015 2020 of South Africa, recognizes the need for youth to take a lead in development-related issues (RSA 2015). This presents a gap between the policy regulations and the prevailing situation at the grassroots level. It was also discovered that there was nepotism about awarding of opportunities to youth in the Mkhado community. Likewise, Checkoway (2011) identified uneven participation of youth and suggested that those of favorable socio-economic status are more likely to be involved as compared to the others.

It was also discovered that adults seemingly considered it very risky to place youth in leadership positions. In this regard, youth retain a passive participant's status, as they were not trusted. This also meant that youth were not involved in any serious matters or discussions as their capabilities were not trusted. This is in line with the findings by Peteru (2008), who highlighted the diminishing status of youth in communities as a result of stereotypes. The stereotype is often based on undesirable characteristics amounting to risky behavior. It is however important for adults to recognize that young people are part of the community and not threats. Youth need to be supported in their endeavor to take part in development-related activities to boost their selfesteem and efficacy (Brennan 2008). As such, there is a need for creating physical and social spaces, where the two groups can meet and iron out their differences as a step towards activating youth participation.
Facilitating attitude change among adults was also seemingly desirable in the community. Youth desire to be viewed as active participants who can contribute to community development rather than mere followers. Youth also indicated that adults did not try to encourage them by giving them leadership positions. Giving youth leadership positions can be a sign of reaching out to them.

\section{CONCLUSION}

The study concludes that youth in selected areas of Makhado municipality was faced with many obstacles that hindered their participation in community development activities. Most of the factors were resident within the way adults related and treated youth concerning community development. It can also be concluded that youth believed that if they are accorded the opportunity to demonstrate their abilities in leading community development initiatives, they will engage in development work. However, this can only be achieved if the adults, particularly the leaders' attitude regarding the role of youth in development work changes.

\section{RECOMMENDATIONS}

Given the findings presented above, it can be recommended that community leaders should find amicable ways of mainstreaming youth into all community plans and development work. There is also a need to ensure that the national policies regarding youth integration and participation are implemented at the community level. Since this study only gathered information from youth, there is a need to establish the views of adults and leaders so that holistic strategies for promoting youth participation are sought.

\section{REFERENCES}

African Youth Charter 2006. Adopted by the Seventh Ordinary Session of the Assembly, held in Banjul, Gambia, 2 July 2006. African Union.

African Youth Charter 2006. From <http://www.au.int/ en/sites/default/files/African_youth_charter.pdf> (Retrieved on 13 May 2015).

Angba A, Adesope O, Aboh C 2009. Effect of socioeconomic characteristics of rural youths on their attitude towards participation in community development projects. International NGO Journal, 4(8): 348-351. 
Brennan MA 2008. Conceptualizing resiliency: An interactional perspective for community and youth development. Child Care in Practice 14(1): 55-64.

Benson K 2012. Power and displacement in women's histories of the urbanization of poverty in South Africa. In: B Gardener, F Winddance Twine (Eds.): Geographies of Privilege: Local, Global and Transnational Sites. UK: Routledge (Forthcoming).

Benson PL, Scales PC, Hamilton SF, Sesma Jr A 2006. Positive youth development so far: Core hypotheses and their implications for policy and practice. Search Institute, 3(1): 56-67.

Booyens M, Crause E 2012. Excluded from education and work: Perceptions of at-risk youth. Social Work/ Maatskaplike Werk, 48(3): 201-215.

Benson PL, Pittman K 2001. Moving the youth development message: Turning a vague idea into a moral imperative. In: PL Benson, KJ Pittman (Eds.): Trends In Youth Development: Visions, Realities, and Challenges. Norwell, MA: Kluwer Academic, pp. vii-xii.

Bridges W 2001. The Way of Transition: Embracing Life's Most Difficult Moments. USA: Perseus Pub.

Campbell D, Erbstein N 2012. Engaging youth in community change: Three key implementation principles. Community Development, 43(1): 63-79.

Charles H 2006. The Commonwealths' response to global challenges facing youth in the $21^{\text {st }}$ century. Commonwealth Youth and Development, 4(2): 4447.

Checkoway B 2015. What is youth participation? Children and Youth Services Review, 33: 340-345.

Chess C, Purcell K 2009. Youth participation and the environmental community projects: Do we know what works? Environmental Science and Technology, 33(16): 2685-2692.

Dungumaro E, Madulu N 2011. Youth participation in integrated water resources management: The case of Tanzania. Journal of Physics and Chemistry of the Earth, 3(4): 1009-1014.

Euromonitor International 2012. The World's Youngest Populations. Market Research Blog.

Jobson J 2011. Interrogating Youth Leadership Development in South Africa: Overview and Leadership for a Winning Nation Strategy. Cape Town, South Africa: DG Murray Trust.

Kativhu S, Francis J, Kilonzo B 2017. Examination of the determinants of youth voluntary participation in rural community development: The case of $\mathrm{Mu}-$ toko District, Zimbabwe. Studies of Tribes and Tribals, 15(1): 45-52.

Kottak P 2002. Anthropology: The Exploration of $\mathrm{Hu}$ man Diversity. $12^{\text {th }}$ Edition. New York: McGraw Hill.
Lucie M, Mbabaizize M, Shukla J 2016. Factors influencing youth participation in community based development projects in Rwanda: A case study Saemaul Zero Hunger Communities Project in Nyamagabe district. European Journal of Business and Social Sciences, 5(6): 152 - 166.

Mokwena S 2002. Youth participation: Taking the idea to the next level: A challenge to youth ministers. Commonwealth Youth and Development, 1(2): 87108.

Nikkhah HA, Redzuan M 2009. Participation as a medium of empowerment in community development. European Journal of Social Sciences, 11(1): 170176.

Peteru P 2008. Youth development: A Pacific context. Commonwealth Youth and Development, 6(1): 2335.

RSA 2013. Makhado Municipality Draft Annual Report 2012/2013 Financial Year. From <http://mfma.treasury. gov.za/Documents/06.\%20Annual\%20Reports/2012-13/ 02.\% 20Local\%20municipalities/LIM344\%20 Makhado/ LIM344\%20 Makhado\%20Draft\%20Annual\% 20report \%202012-13.pdf> (Retrieved on 12 March 2015).

Republic of South Africa 2015. National Youth Policy 2015-2020. Office of the Presidency. From <www. thepresidency.gov.za/.../NY P\%20 Policy\%2 02020\%20Report.pdf> (Retrieved on 26 August 2015).

Rhodes JE, DuBois DL 2006. Understanding and facilitating the youth mentoring movement. Social Policy Report. Giving Child and Youth Development. Knowledge Away, 20(3): 3-20.

STATSSA 2013. General Household Survey 2013, P03182013. Pretoria. From <http://beta2.statssa. gov.za/?page_id=993\&id=makhado-municipality $>$ (Retrieved on 8 August 2015).

The Commonwealth Plan of Action for Youth Empowerment 2007-2015. Young People, Including

Commonwealth Youth Caucus Representatives Report. United Kingdom.

Toffler A 2005. Quotes on Young People. From <http:/ /www.freechild.org/quotations.htm $>$ (Retrieved on 8 August 2015).

United Nations 2005. World Youth Report: Young People Today and in 2015. United Nations Publications.

United Nations High Commissioner for Refugees (UNHCR) 2010. Working for Refugees on Europe's Outer Borders, 18 May 2010. From <http://www.unhcr.org/ 4bf29c8b6.html> (Retrieved on 11 July 2015).

Paper received for publication in June, 2017

Paper accepted for publication in July, 2018 